\title{
Release behavior and toxicity profiles towards A549 cell lines of ciprofloxacin from its layered zinc hydroxide intercalation compound
}

\author{
Ahmad Faiz Abdul Latip ${ }^{1}$, Mohd Zobir Hussein ${ }^{1 *}$, Johnson Stanslas ${ }^{2}$, Charng Choon Wong ${ }^{2}$ and Rohana Adnan ${ }^{3}$
}

\begin{abstract}
Background: Layered hydroxides salts (LHS), a layered inorganic compound is gaining attention in a wide range of applications, particularly due to its unique anion exchange properties. In this work, layered zinc hydroxide nitrate (LZH), a family member of LHS was intercalated with anionic ciprofloxacin (CFX), a broad spectrum antibiotic via ion exchange in a mixture solution of water:ethanol.

Results: Powder x-ray diffraction (XRD), Fourier transform infrared (FTIR) and thermogravimetric analysis (TGA) confirmed the drug anions were successfully intercalated in the interlayer space of LZH. Specific surface area of the obtained compound was increased compared to that of the host due to the different pore textures between the two materials. CFX anions were slowly released over 80 hours in phosphate-buffered saline (PBS) solution due to strong interactions that occurred between the intercalated anions and the host lattices. The intercalation compound demonstrated enhanced antiproliferative effects towards A549 cancer cells compared to the toxicity of CFX alone.

Conclusions: Strong host-guest interactions between the LZH lattice and the CFX anion give rise to a new intercalation compound that demonstrates sustained release mode and enhanced toxicity effects towards A549 cell lines. These findings should serve as foundations towards further developments of the brucite-like host material in drug delivery systems.
\end{abstract}

Keywords: Drug delivery, Layered zinc hydroxide nitrate, Ciprofloxacin, Anion exchange, Sustained release, Release mechanisms, Cytotoxicity

\section{Background}

The application of nanotechnology to drug delivery is nowadays a growing research field. A wide variety of nano-sized drug carriers has found niche in the field, owing to their unique structures which give rise to new generations of therapeutic agents and medical devices [1]. The main advantages of the nano-based drug delivery over the traditional ones are manifold: enhanced biodistribution and pharmacokinetics of drug [2], improved delivery of poorly water-soluble drugs [3], lowered systemic toxicity of drug while being concentrated on the target organ

\footnotetext{
* Correspondence: mzobir@putra.edu.my

${ }^{1}$ Materials Synthesis and Characterization Laboratory (MSCL), Institute of Advanced Technology (ITMA), Universiti Putra Malaysia UPM, 43400 Serdang, Selangor, Malaysia

Full list of author information is available at the end of the article
}

[4] and ability to optimize drug release rate towards achieving better patient compliance [5].

Layered hydroxides salts (LHS) is a layered inorganic compound which shares structural resemblance to anionic clay, layered double hydroxides (LDH). The structure of LDH is derived from that of brucite, $\left[\mathrm{Mg}(\mathrm{OH})_{2}\right]$ and may be represented by the formula $\left[\mathrm{M}^{2+}{ }_{1-\mathrm{x}} \mathrm{M}^{3+}{ }_{\mathrm{x}}(\mathrm{OH})_{2}\right]\left(\mathrm{A}^{\mathrm{n}-}\right)_{\mathrm{x} / \mathrm{n}}$. $\mathrm{mH}_{2} \mathrm{O}$; where $\mathrm{M}^{2+}$ and $\mathrm{M}^{3+}$ are divalent and trivalent cations of the lattice, respectively, $x$ is equal to the ratio $\left[\mathrm{M}^{3+} /\left(\mathrm{M}^{2+}+\mathrm{M}^{3+}\right)\right]$ and $\mathrm{A}^{\mathrm{n}-}$ is an anion [6]. In relation to LDH, its LHS sibling may undergo structural modifications based on different type of metal cation that is present in the compound lattice. It has been reported that nitrate group precursor are directly involved in the formation of LHS of $\mathrm{Cu}_{2}(\mathrm{OH})_{3} \mathrm{NO}_{3}, \mathrm{La}(\mathrm{OH})_{2} \mathrm{NO}_{3} \mathrm{H}_{2} \mathrm{O}$ and $\mathrm{Mg}_{2}(\mathrm{OH})$ ${ }_{3} \mathrm{NO}_{3}$ via coordination with the lattice cation through one oxygen atom of the nitrate ion $[7,8]$.

\section{Chemistry Central}


In $\mathrm{Zn}_{5}(\mathrm{OH})_{8}\left(\mathrm{NO}_{3}\right)_{2} \cdot 2 \mathrm{H}_{2} \mathrm{O}$ (denoted as $\mathrm{LZH}$ ), the brucite-like lattice is modified wherein one-fourth of octahedrally coordinated $\mathrm{Zn}^{2+}$ cations are absent, thus creating empty octahedral sites. On either side of the empty octahedra are found tetrahedrally coordinated $\mathrm{Zn}^{2+}$ cations with the hydroxyl ions and water molecules. In this compound, the nitrate ion is not coordinated with the $\mathrm{Zn}^{2+}$ cations and located in the interlayer space of LZH [9].

LHS is currently gaining attraction due to its simple method of synthesis [10], as a precursor for a wide band gap $\mathrm{ZnO}[11]$, for the synthesis of layered double hydroxide salts [12] and anion exchange properties [13]. A wide variety of guest molecules has been intercalated into the interlayer region of LHS, mainly via ion exchange process, ranging from anionic dyes [14], porphyrin sensitizers [15] and an anti corrosive compound [16]. In particular, LHS has demonstrated the ability to extend the release period of bioactive molecules [17] and drug molecules [18], prompting more investigations towards potential applications of LHS in drug delivery systems.

Ciprofloxacin (CFX) is a wide spectrum antibiotic that belongs to the quinolone family [19]. The antimicrobial activities of CFX are mainly achieved through the chlorine-substituted N-1 cyclopropyl group which enhances cell penetration and improves activity against DNA gyrase and topoisomerase IV enzymes [20]. Although CFX is known as a safe drug, there are cases of side effects associated with CFX such as anaphylaxis and pulmonary edema [21,22]. CFX suffers from moderate oral bioavailability [23], as it chelates with calcium-, magnesium- and aluminium-containing salts upon concomitant administration [24]. In drug delivery systems, CFX has been used with various drug carriers such as polymeric nanoparticles [25-27], cyclodextrin [28], chitosan [29], montmorillonite [30] and calcium apatite [31].

In this paper, we prepared an inorganic drug carrier based on LZH host material intercalated with a model drug, CFX. Considering LZH possesses higher layer charge density compared to that of $\mathrm{LDH}$ counterpart [32], we are prompted to examine the release behavior of the intercalated CFX anions from LZH in phosphatebuffered saline solution, after which the corresponding release mechanisms was further established. In addition, the toxicity profile of the intercalation compound was evaluated against adenocarcinomic human alveolar basal epithelial cancer cell line to demonstrate synergistic effects between drug-host interactions towards cells growth inhibition [33].

\section{Materials and methods Materials}

Ciprofloxacin, $\mathrm{C}_{17} \mathrm{H}_{18} \mathrm{FN}_{3} \mathrm{O}_{3}$ (1-cyclopropyl-6-fluoro4-oxo-7-piperazin-1-yl-quinoline-3-carboxylic acid, molecular weight $331.34 \mathrm{~g} / \mathrm{mol}$ ) was purchased from
Sigma Aldrich Co. Ltd. and was used as received. All solutions were prepared using deionized water.

\section{Synthesis of LZH}

Layered zinc hydroxide nitrate (LZH) was synthesized according to the modified version of previous report [32]. An aqueous solution of $0.4 \mathrm{~mol} / \mathrm{L} \mathrm{Zn}\left(\mathrm{NO}_{3}\right)_{2} \cdot 6 \mathrm{H}_{2} \mathrm{O}$ was prepared in $100 \mathrm{ml}$ volumetric flask. To this solution, $0.8 \mathrm{~mol} / \mathrm{L} \mathrm{NaOH}$ solution was added dropwise, under vigorous magnetic stirring, until $\mathrm{pH}$ of the mixture reached $\mathrm{pH}$ 7.0. The resulting precipitates were aged at $70^{\circ} \mathrm{C}$ for $18 \mathrm{~h}$, washed thoroughly with deionized water and dried in an oven at $60^{\circ} \mathrm{C}$.

\section{Synthesis of Z-CFX}

The intercalation compound, Z-CFX was obtained via anion exchange between nitrate ion of precursor $\mathrm{LZH}$ and anionic ciprofloxacin (CFX) in a mixture solution of water:organic solvent. Approximately $0.2 \mathrm{~g}$ of finely ground $\mathrm{LZH}$ was dispersed in $25 \mathrm{ml}$ of water:ethanol mixture solution containing $0.9 \mathrm{~g}$ of CFX under vigorous stirring. The $\mathrm{pH}$ of the exchange medium was adjusted by slow titration of $1.0 \mathrm{~mol} / \mathrm{L} \mathrm{NaOH}$ until $\mathrm{pH} 8.0$ was achieved. The mixture was left under stirring for $24 \mathrm{~h}$. The resulting product was collected by washing the precipitates thoroughly with deionised water and ethanol and was dried at $60^{\circ} \mathrm{C}$ for $24 \mathrm{~h}$.

\section{In vitro release}

The release of CFX from the intercalation compound was conducted in phosphate-buffered saline solution (PBS) pH 7.4 wherein $0.6 \mathrm{mg}$ of Z-CFX were immersed in the PBS solution and the accumulated release of CFX was measured at $\lambda_{\max }=276.3 \mathrm{~nm}$ using a Perkin Elmer UV-Vis Spectrophotometer Lambda 35.

\section{Cell culture}

Human lung alveolar carcinoma epithelial (A549) cells were cultured in RPMI 1640 medium under a humidified atmosphere $\left(5 \% \mathrm{CO}_{2}\right.$ plus $95 \%$ air $)$ at $37^{\circ} \mathrm{C}$. The medium was supplemented with $10 \%$ heat-inactivated fetal bovine serum, $2 \mathrm{mM}$ of L-glutamine, 100 units/ml of penicillin and $100 \mu \mathrm{g} / \mathrm{ml}$ of streptomycin.

\section{MTT assay}

MTT (3-(4,5-dimethylthiazole-2-yl)-2,5-diphenyltetrazolium bromide) cell viability assay was used to investigate the toxic effect of Z-CFX, ZLH and CFX. Cells $\left(2 \times 10^{3}\right.$ cells $\left./ 100 \mu \mathrm{l}\right)$ were seeded onto 96 -well plates and incubated overnight at $37^{\circ} \mathrm{C}$ under a $5 \% \mathrm{CO}_{2}$ atmosphere. After cells had stabilized, fresh medium containing either Z-CFX, ZLH or CFX at different concentrations (0.5, 5.0, 50.0 and $500.0 \mu \mathrm{g} / \mathrm{mL}$ ) was added and incubation continued for $72 \mathrm{~h}$. After the incubation, $10 \mu \mathrm{L}$ of MTT 
solution was added to each well and incubated further for $4 \mathrm{~h}$, the reaction was terminated by adding $100 \mathrm{~mL}$ of $10 \% \mathrm{SDS}$ in $0.01 \mathrm{~mol} / \mathrm{L} \mathrm{HCl}$ solution. The absorbance was measured on a microplate reader at wavelength $570 \mathrm{~nm}$.

\section{Characterizations}

Powder $\mathrm{x}$-ray diffraction (PXRD) patterns were recorded on an ITAL APD 2000 powder diffractometer using $\mathrm{CuK}_{\alpha}$ radiation $(\lambda=1.5418 \AA)$ at $40 \mathrm{kV}$ and $30 \mathrm{~mA}$. The data was collected from $2-60^{\circ}$ at a dwell time of $2^{\circ}$ per minute. Fourier transform infrared (FTIR) spectra were recorded in the range $400-4000 \mathrm{~cm}^{-1}$ at a $4 \mathrm{~cm}^{-1}$ resolution on a Perkin-Elmer 1752X (Boston, MA) spectrophotometer using the potassium bromide $(\mathrm{KBr})$ pellet technique; approximately $1 \%$ sample was mixed in $100 \mathrm{mg}$ of spectroscopic grade $\mathrm{KBr}$ and the pellet was pressed at 10 tons. The atomic weight percent of carbon, hydrogen and nitrogen was determined using CHNS932 (LECO Instruments St Joseph, MI). The zinc ion composition was determined using a Perkin-Elmer inductively coupled plasma-atomic emission spectrometry (ICP-AES) model Optima 2000DV under standard conditions. Thermogravimetric and differential thermogravimetric analyses (TGA/DTG) were carried out in $150 \mu \mathrm{L}$ alumina crucibles using a Metter-Toledo instrument model TGA851e (Greifensee, Switzerland) at a heating rate of $10^{\circ}$ per minute in the range of $25-900^{\circ} \mathrm{C}$ with the sample amount being 5-10 $\mathrm{mg}$ in nitrogen atmosphere. The surface morphology of the samples was observed by a field emission scanning electron microscope (FESEM), FEI Nova Nanosem 230 with an acceleration voltage of $25 \mathrm{kV}$. Prior to analysis, the samples were mounted on aluminum stub over double-coated carbon film. Textural characterisations were carried out using a nitrogen gas adsorption-desorption technique at $77 \mathrm{~K}$ using a Micromeritics ASAP2000. The sample was degassed in an evacuated heated chamber at $100^{\circ} \mathrm{C}$ overnight. Pore size distributions were calculated using the Barrett-Joyner-Halenda (BJH) model on the desorption branch.

\section{Results and discussions} $X$-ray diffraction analysis

Figure 1 shows XRD patterns of LZH host material and $\mathrm{Z}-\mathrm{CFX}$ intercalation compound. The diffraction patterns are characteristic of lamellar solid materials as indicated by sharp, intense basal reflections at low $2 \theta$ values and weaker non-basal reflections at higher angles [10]. Figure 1a displays the XRD pattern typical of LZH intercalated with nitrate ions [34]. The basal reflections of LZH are shifted to lower $2 \theta$ values as anion exchange is completed, indicating the formation of ciprofloxacin-LZH intercalation compound. Accordingly, the basal spacing of

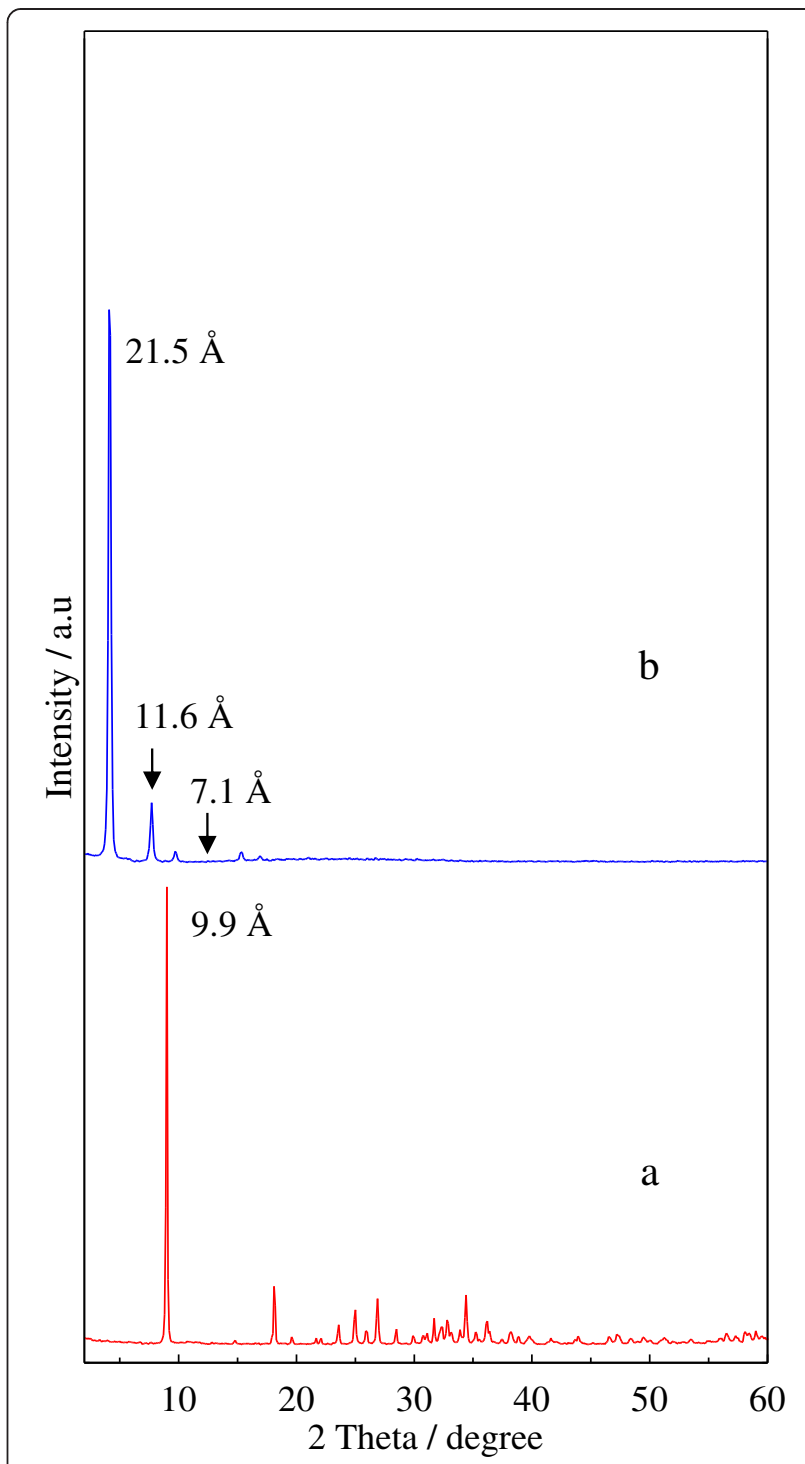

Figure 1 XRD patterns of (a) LZH and (b) Z-CFX. (a) host material, LZH. (b) intercalation compound, Z-CFX.

LZH expands from $9.9 \AA$ to $21.5 \AA$ in Z-CFX (Figure 1b). Therefore, the interlayer height of Z-CFX is estimated to be about $14.1 \AA$; obtained by subtracting the layer thickness plus the height of $\mathrm{Zn}^{2+}$ moiety of the lattice from the basal spacing; i.e. $14.1 \AA=21.5-(4.8+2.6) \AA$. The obtained value is larger than the longitudinal length of CFX molecule (Figure 2). Therefore, we propose CFX anions were arranged as intertwined bilayers in the interlayer space [35], wherein the carboxylate groups of CFX were bonded through an oxygen atom to $\mathrm{Zn}^{2+}$ units of the lattice [7]. The proposed arrangement of the intercalated CFX anions in the interlayer space of LZH is illustrated in Figure 3. 


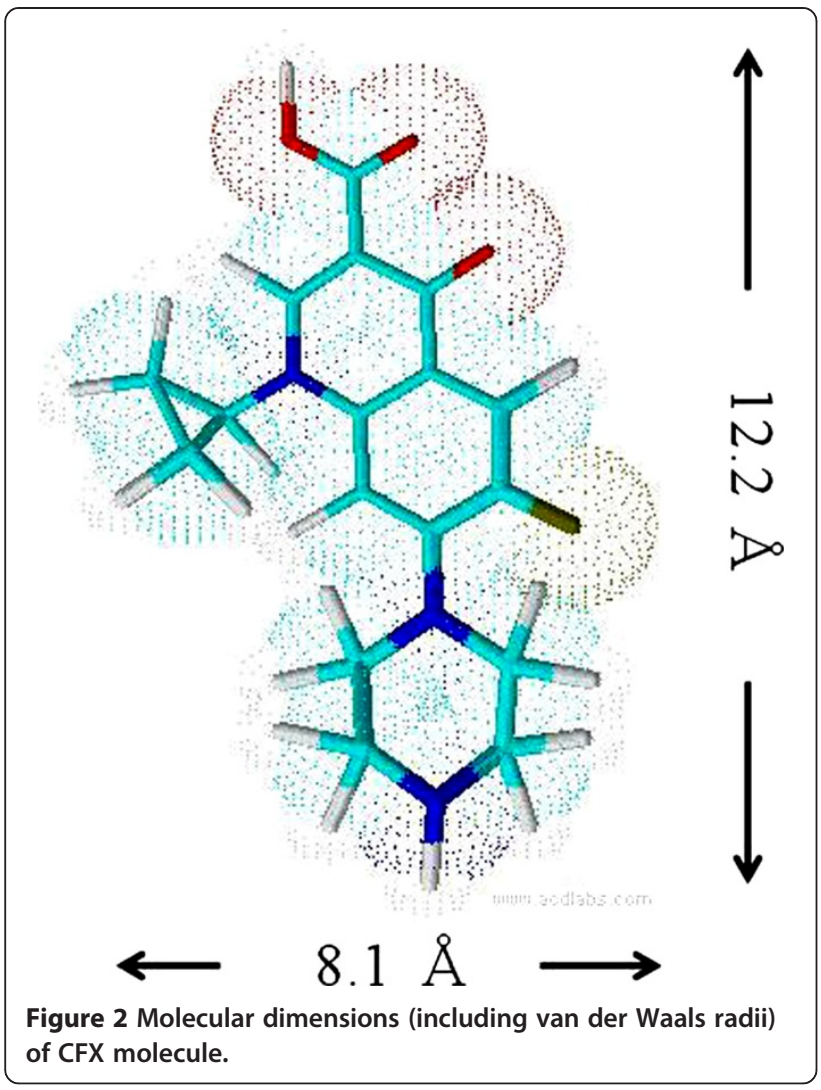

\section{Fourier transform infrared spectroscopy}

Figure 4 shows FTIR spectra of LZH host material, CFX molecule and Z-CFX intercalation compound. Only the main absorption bands are listed for the sake of clarity. In all spectra, broad absorption bands are observed in the range of $3440-3540 \mathrm{~cm}^{-1}$ due to the stretching vibrations of hydroxyl group of the lattice and water

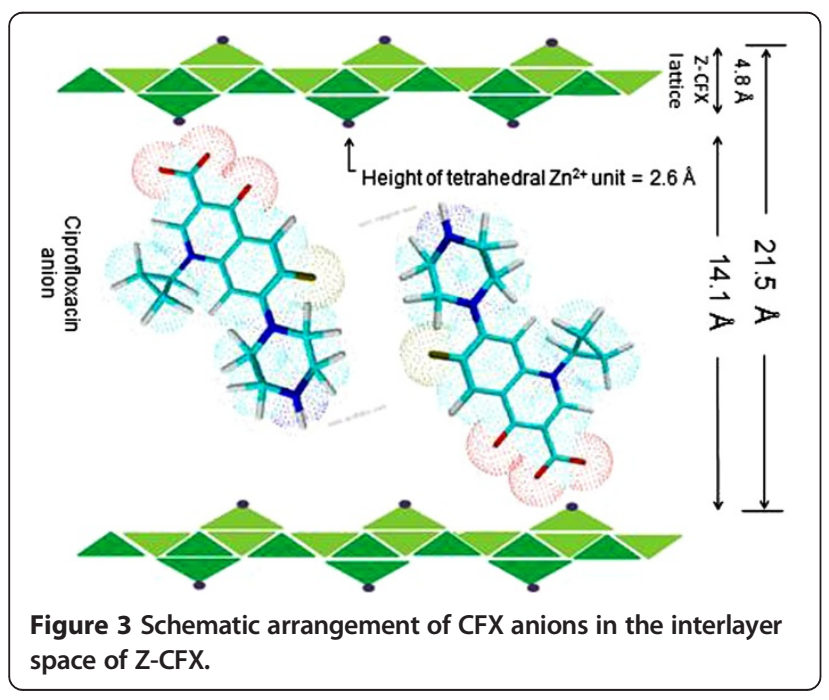

molecules. Figure 4a shows a typical FTIR spectrum of the host material, LZH with nitrate being the counter anion. An absorption band at $1639 \mathrm{~cm}^{-1}$ is attributed to the bending mode of water molecules [36]. At low frequency, bands arising from the lattice vibrations of $\mathrm{Zn}-\mathrm{O}$ and $\mathrm{O}-\mathrm{Zn}-\mathrm{O}$ are detected at 639 and $467 \mathrm{~cm}^{-1}$, respectively. The most intense absorption band in $\mathrm{LZH}$ is found at $1385 \mathrm{~cm}^{-1}$, which is characteristic of free interlayer nitrate group (symmetry $\mathrm{D}_{3 \mathrm{~h}}$ ) [8].

For CFX (Figure 4b), an absorption band at $3375 \mathrm{~cm}^{-1}$ is attributed to the stretching vibrations of amine group. Intense bands at 1711 and $1624 \mathrm{~cm}^{-1}$ are characteristic of the stretching vibrations of carbonyl group of carboxylic acid and ketone, respectively. Bands centered at 1310, 1269 and $1048 \mathrm{~cm}^{-1}$ are assigned to the stretching modes of $\mathrm{C}-\mathrm{N}, \mathrm{C}-\mathrm{C}-\mathrm{C}$ of ketone and $\mathrm{C}-\mathrm{F}$, respectively.

The FTIR spectrum of Z-CFX features main characteristic absorption bands of CFX anions which indicate that the anions were successfully intercalated into the LZH interlayers. Figure 4c depicts the stretching bands of asymmetric and symmetric of carboxylate group of the CFX anions, observed at 1576 and $1385 \mathrm{~cm}^{-1}$, respectively. Generally, difference in wavenumber between the carboxylate stretching bands $\left(\Delta v=v_{\text {asym }}-v_{\text {sym }}\right)$ gives information about the coordination environment of the functional group. Li et al. [36] mentioned that carboxylate group adopting unidentate coordination mode has a larger $\Delta v$ value compared to that of bridging carboxylate; 200 and $150 \mathrm{~cm}^{-1}$, respectively. Since the $\Delta \mathrm{v}$ of $\mathrm{COO}^{-}$of CFX anions is $191 \mathrm{~cm}^{-1}$, we would suggest that the intercalated CFX is coordinately bonded to $\mathrm{Zn}^{2+}$ units of the lattice via one oxygen atom of the functional group.

The spectrum of Z-CFX also displays the other characteristic bands of CFX that were shifted from their initial positions as a result of multiple chemical interactions; electrostatic interactions between CFX anions and LZH lattice [18], as well as hydrogen bonding effect between water molecules and CFX anions [37]. The assignment of the absorption bands in the FTIR spectra of LZH, CFX and Z-CFX is summarized in Table 1.

Table 2 summarizes the elemental analysis data for $\mathrm{Z}-$ CFX and LZH obtained from the CHN analysis and the corresponding stoichiometric formula for both samples. Approximately $42.63 \%$ of CFX was intercalated into the LZH interlayers as determined from the carbon content. Note that there are a small percentage of nitrate in the intercalation compound which indicates the total anion exchange was not achieved. Nonetheless, the stretching band of the remaining nitrate at $1385 \mathrm{~cm}^{-1}$ is not observed since it may have been obscured by the symmetric band of carboxylate of CFX anions [38]. There is also a small percentage of carbonate anions in the precursor $\mathrm{LZH}$ and in the intercalation compound $\mathrm{Z}-\mathrm{CFX}$, a feature commonly observed in anionic clays 


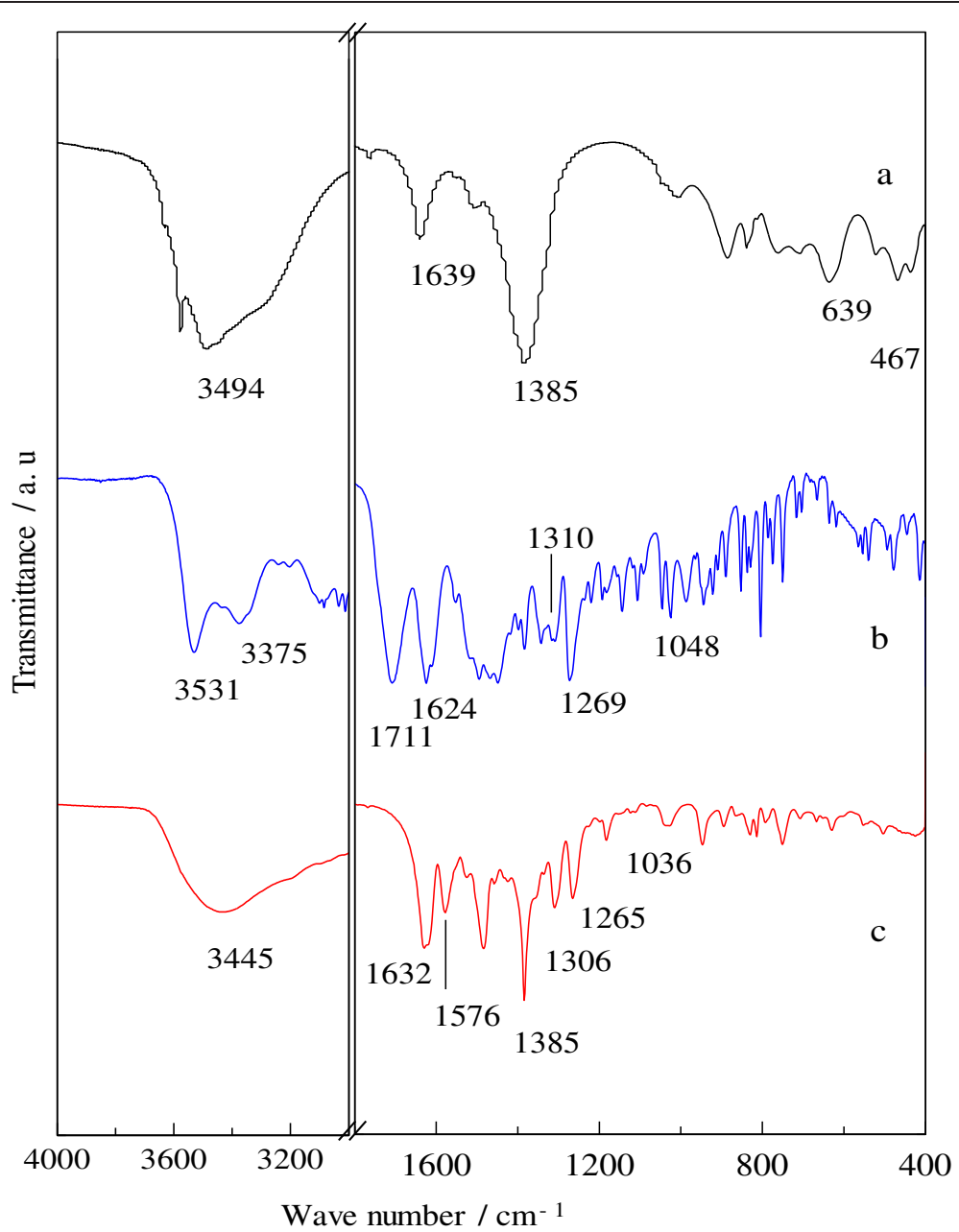

Figure 4 FTIR spectra of (a) LZH, (b) CFX and (c) Z-CFX. (a) host material, LZH. (b) free drug molecule, CFX. (c) intercalation compound, Z-CFX.

Table 1 Assignment of FTIR absorption bands of Z-CFX, CFX and LZH

\begin{tabular}{cccc}
\hline Assignment & \multicolumn{3}{c}{$\mathbf{c m}^{-\mathbf{1}}$} \\
\cline { 2 - 4 } & LZH & CFX & Z-CFX \\
\hline $\mathrm{u}(\mathrm{OH})$ of lattice, & $3670-3200$ & - & $3670-3200$ \\
$\mathrm{U}(\mathrm{O}-\mathrm{H}) \mathrm{COOH}$, & & & \\
$\mathrm{U}(\mathrm{N}-\mathrm{H}) \mathrm{NH}$ & - & 1711 & - \\
$\mathrm{U}(\mathrm{COOH})$ & $1639 \mathrm{w}$ & - & - \\
$\delta(\mathrm{OH})$ of $\mathrm{H}_{2} \mathrm{O}$ & - & $1624 \mathrm{~s}$ & $1632 \mathrm{~s}$ \\
$\mathrm{u}(\mathrm{C}=\mathrm{O})$ ketone & - & - & 1579 \\
$\mathrm{U}_{\text {asym }}\left(\mathrm{COO}^{-}\right)$ & $1385 \mathrm{~s}$ & - & $1385 \mathrm{sup}$ \\
$\mathrm{U}\left(\mathrm{NO}_{3}^{-}\right)$ & - & - & $1385 \mathrm{sup}$ \\
$\mathrm{U}_{\text {sym }}\left(\mathrm{COO}^{-}\right)$ & - & $1310 \mathrm{~m}$ & $1306 \mathrm{~m}$ \\
$\mathrm{U}(\mathrm{C}-\mathrm{N})$ & - & $1269 \mathrm{~m}$ & $1265 \mathrm{~m}$ \\
$\mathrm{U}(\mathrm{C}-\mathrm{C}-\mathrm{C})$ ketone & - & $1048 \mathrm{~m}$ & $1036 \mathrm{w}$ \\
$\mathrm{U}(\mathrm{C}-\mathrm{F})$ & &
\end{tabular}

Abbreviations: $S$ sharp, $M$ medium, $W$ weak, Sup superimposed. due to strong affinity of the anions towards highly positively charged clay lattice $[39,40]$. The normal absorption band of carbonate ion within $1360-1380 \mathrm{~cm}^{-1}$ maybe overlapped with the stretching vibration of nitrate ion and the symmetric vibration of the carboxylate group of CFX [41].

\section{Thermal analysis}

Figure 5 shows TGA and DTG profiles of Z-CFX. The thermal decomposition of Z-CFX follows the general route observed in LHS intercalated with organic anions [42]. The first step occurs from ambient up to $200^{\circ} \mathrm{C}$ with respective to the weight loss of $12.5 \%$ which is due to the removal of adsorbed and intercalated water. The compound further undergoes a $26 \%$ of weight loss in the region of $240-500^{\circ} \mathrm{C}$ which is attributed to the dehydroxylation of the hydroxide layers as well as partial decomposition of the intercalated CFX anions. The final step records a $35 \%$ weight loss with the major peak occurs around $827^{\circ} \mathrm{C}$ (temperature range $680-928^{\circ} \mathrm{C}$ ) 
Table 2 Elemental analysis data, chemical formula and textural properties of LZH and Z-CFX

\begin{tabular}{|c|c|c|c|c|c|c|c|c|}
\hline \multirow[t]{2}{*}{ Sample proposed formula } & \multicolumn{5}{|c|}{ Weight percentage (\%) } & \multirow{2}{*}{$\begin{array}{l}\text { BET surface } \\
\text { area }\left(\mathrm{m}^{2} / \mathrm{g}\right)\end{array}$} & \multirow{2}{*}{$\begin{array}{l}\text { Pore volume } \\
\qquad\left(\mathrm{cm}^{3} / \mathrm{g}\right)\end{array}$} & \multirow{2}{*}{$\begin{array}{l}\text { Average pore } \\
\text { diameter (nm) }\end{array}$} \\
\hline & $\mathrm{C}$ & $\mathbf{H}$ & $\mathbf{N}$ & $\mathrm{H}_{2} \mathrm{O}$ & $\mathrm{Zn}$ & & & \\
\hline $\mathrm{LZH}$ & 0.38 & 1.57 & 3.20 & 11.4 & 70.67 & 14.20 & 0.14 & 38.79 \\
\hline \multicolumn{9}{|l|}{$\mathrm{Zn}_{5}(\mathrm{OH})_{8}\left(\mathrm{NO}_{3}\right)_{1.02}\left(\mathrm{CO}_{3}\right)_{0.07} \cdot 2.93 \mathrm{H}_{2} \mathrm{O}$} \\
\hline Z-CFX (Molecular weight: $872.53 \mathrm{~g} / \mathrm{mol}$ ) & 26.27 & 3.27 & 6.17 & 12.33 & 45.26 & 26.51 & 0.17 & 25.94 \\
\hline
\end{tabular}

which is ascribed to the complete decomposition of amorphous mixture of salts generated during the initial drug decomposition [15].

\section{Textural analysis}

Figure 6a illustrates Type IV adsorption-desorption isotherm following the IUPAC classification which reveals the mesoporous nature of $\mathrm{Z}-\mathrm{CFX}$. The adsorption isotherm elucidates monolayer adsorptions commenced on the pore surface at low partial pressures followed by multilayer formation up to high partial pressures. There was no limiting adsorption of $\mathrm{N}_{2}$ gas observed at high partial pressures suggesting the presence of macropores

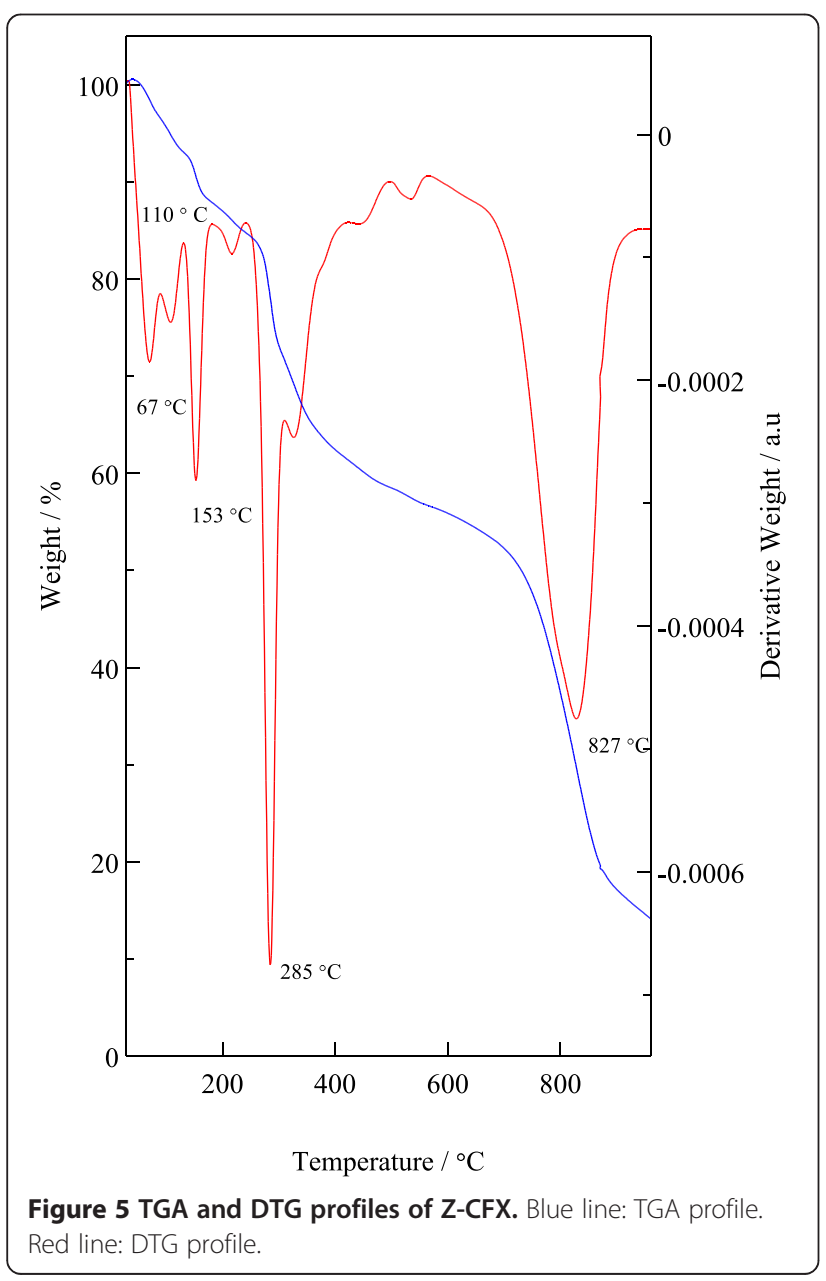

[43]. This finding is in agreement with the wide distribution of pore size in Figure 6c, ranging from 1-95 nm, whereas the maximum size distribution being $2 \mathrm{~nm}$. The hysteresis loop, indicative of capillary condensation in the mesopores occurred on the desorption isotherm down to partial pressure of around 0.25 . The hysteresis loop which belongs to Type H3 hysteresis loop is characteristic of aggregates of plate-like particles [44].

Table 2 summarizes the specific surface area (SSA), the pore volume and the average pore diameter for $\mathrm{LZH}$ and Z-CFX as determined from the Brunaeur, Emmett and Teller (BET) method and the Barrett, Joyner and Halenda $(\mathrm{BJH})$ method. It is worth mentioning that the CFX-intercalated LZH shows a larger surface area of $27 \mathrm{~m}^{2} / \mathrm{g}$ compared to that of the host with nitrate as the counter anion, $\mathrm{LZH}$ which is $14 \mathrm{~m}^{2} / \mathrm{g}$. This finding is dissimilar from another group which observed the decreased in surface area value of LDH after being intercalated with organic anions [45]. Moreover, reports on the $\mathrm{N}_{2}$ adsorption-desorption of LZH intercalated with drug anions are rather scarce for comparison purposes with our aforesaid findings [46].

Recently, Hussein and co-workers reported that surface area of hippurate-LZH intercalation compound was decreased compared to that of the starting material, $\mathrm{ZnO}$ [47]. Hippuric acid was first dissolved in dimethyl sulfoxide before it was added to the $\mathrm{ZnO}$ suspension. On the contrary, in this work, CFX was dissolved in a mixture of water:ethanol solution to solubilize the drug prior to its intercalation into LZH since the drug CFX has poor solubility in aqueous solution. In a related finding, Malherbe et al. [48] showed that the surface area of hexacyanoferrate-intercalated LDH had increased when the intercalation compound was obtained via anion exchange in water-organic solvent mixtures. The group concluded that the inherent properties of organic solvents were responsible for the increased surface area of the obtained materials. We would attribute the increased in surface area of Z-CFX compared to LZH is due to different pore texture of the resulting material, which is very much depending on the method of synthesis.

\section{Morphology analysis}

Figure 7 depicts the FESEM micrographs of the hybrid material, Z-CFX and the host material, LZH. In Figure 7a, 

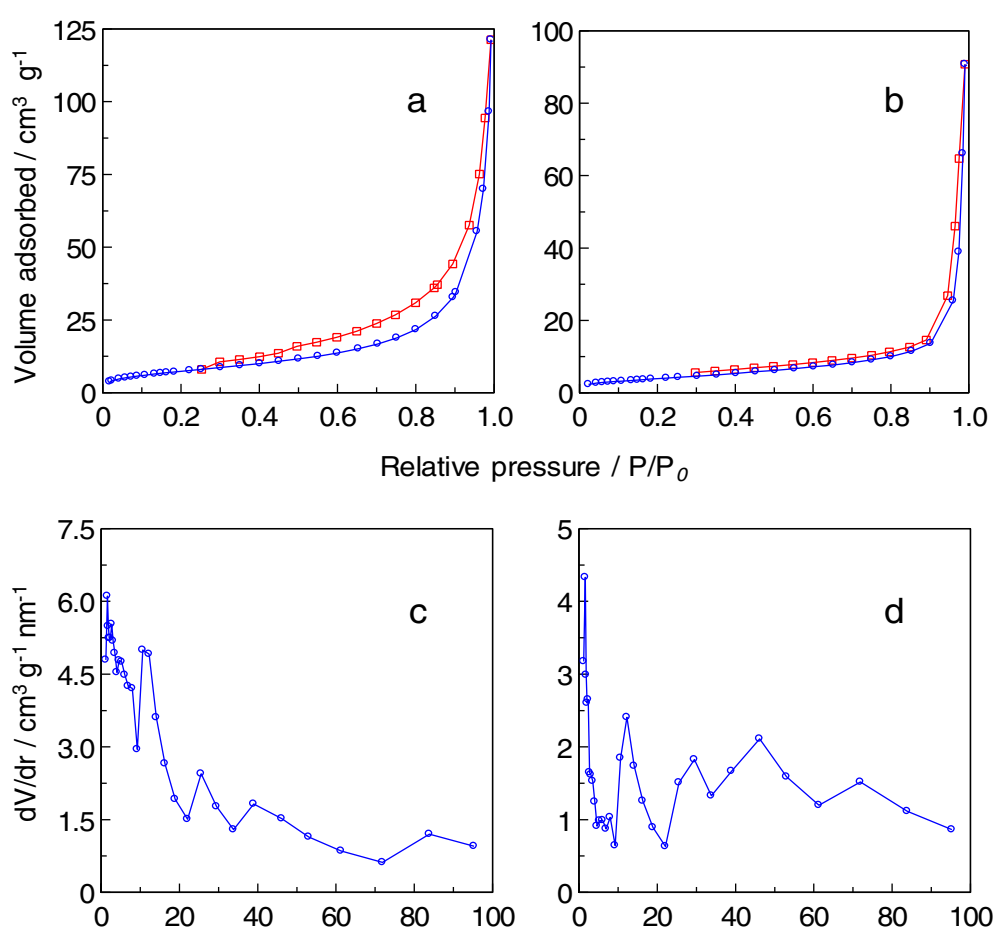

Pore diameter / $\mathrm{nm}$

Figure 6 Nitrogen adsorption-desorption isotherms of (a) Z-CFX and (b) LZH, and pore size distribution of (c) Z-CFX and (d) LZH.

(a) nitrogen adsorption-desorption isotherm of Z-CFX. (b) nitrogen adsorption-desorption isotherm of LZH. (c) pore size distribution of Z-CFX. (d) pore size distribution of $\mathrm{LZH}$.

LZH exhibited aggregated plate-like particles which are stacked on top of each other. The intercalation of CFX molecules into the host, however, did not significantly change the morphology of Z-CFX (Figure 7b). Yang et al. [32] observed similar phenomenon in which no appreciable changes are observed in the plate-like morphology of the indole-3-acetic-intercalated zinc layered hydroxides and the parent layered zinc hydroxides.

\section{Release study}

Release of drug anion from the hybrid material was done in the PBS solution $\mathrm{pH} 7.4$ to evaluate its potentials as a drug carrier. Figure 8 shows the release profile of CFX which was achieved in a slow, sustained behaviour over $80 \mathrm{~h}$ that was in contrast with that of the physical mixture which reached an equillibrium within $20 \mathrm{~min}$ (inset Figure 8). The exceptionally slow, sustained release of Z-CFX was ascribed to the coordination bond between tetrahedral $\mathrm{Zn}^{2+}$ units with the intercalated anions as determined from the FTIR spectra (Figure 4). CFX anions were strongly held to the extent that their diffusion from the interlayer into the exchange medium solution was retarded, owing to the fact that total release of CFX was not achieved (CFX release at equillibrium was approximately $56 \%$ ).
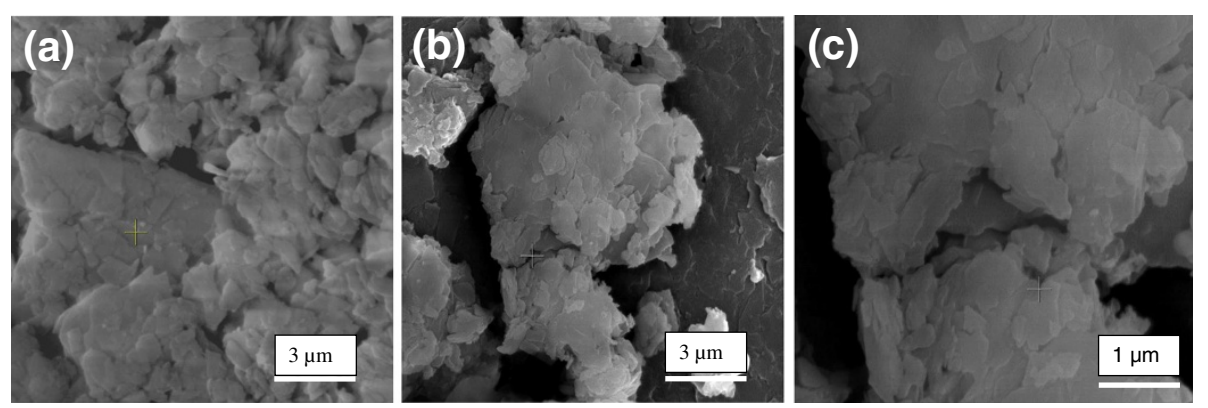

Figure 7 SEM images of (a) LZH (b) Z-CFX (c) Z-CFX observed at high resolution. (a) host material, LZH. (b) intercalation compound, Z-CFX. 


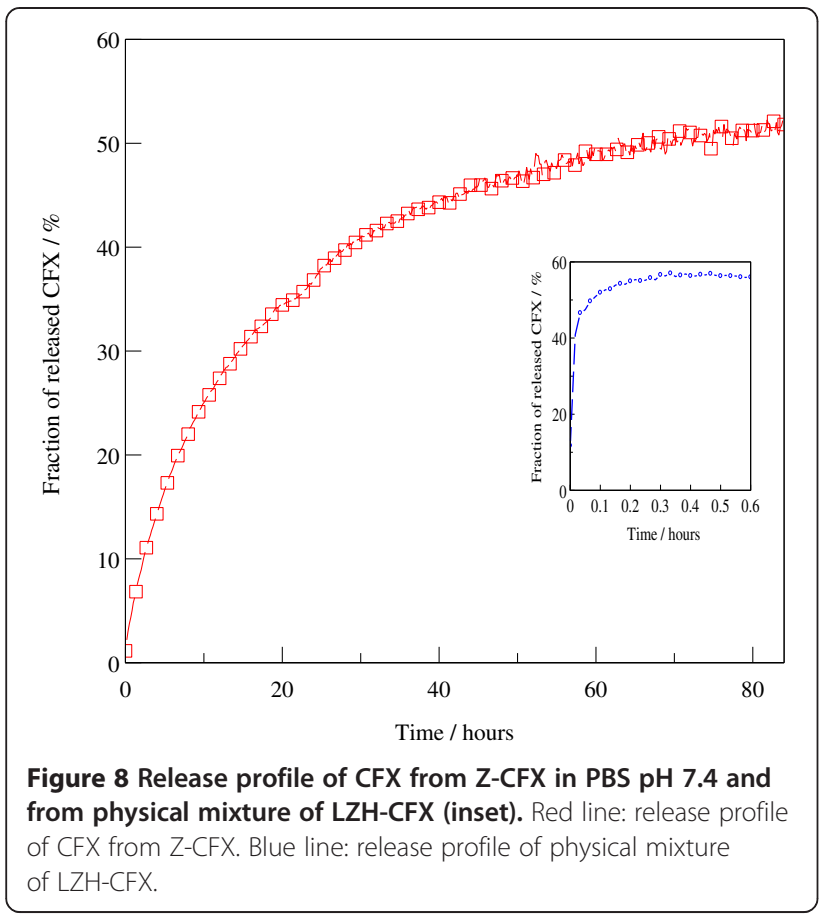

In order to gain insights into the mechanisms of CFX release from Z-CFX, we have applied four kinetic models commonly applicable in the kinetic study of drugintercalated layered hydroxides hybrids. The models are:

1. First-order model which demonstrates the release system where dissolution rate depends on the amount of drug present in the intercalation compound and can be mathematically expressed as [49]:

$$
\log \left(\mathrm{C}_{\mathrm{t}} / \mathrm{C}_{\mathrm{o}}\right)=-K_{1} \mathrm{t}
$$

2. Parabolic diffusion model which describes the diffusion-controlled release of a drug from a medium and is generally written as [50]:

$$
\left(1-C_{t} / C_{0}\right) / t=K d t^{-0.5}+\mathrm{a}
$$

3. The modified Freundlich model which explains experimental data on ion exchange and diffusioncontrolled process following the equation [51]:

$$
\left(\mathrm{C}_{\mathrm{o}}-\mathrm{C}_{\mathrm{t}}\right) / \mathrm{C}_{\mathrm{o}}=K \mathrm{mt}^{\mathrm{b}}
$$

4. The Bhaskar model which deals with the diffusioncontrolled release of drug from particles and is summarised in the form [52]:

$$
-\log \left(1-C_{t} / C_{o}\right)=t^{0.65}
$$

In equations $1-4, C_{o}$ and $C_{t}$ are the amount of drugs in the LZH matrix at release time 0 and $t$, respectively, $\mathrm{K}$ is the rate constant, and $\mathrm{a}$ and $\mathrm{b}$ are the constants whose chemical significance is not clearly understood [51].

The release data of CFX were fitted to the above models and the corresponding linear correlation coefficients $\left(R^{2}\right)$ were obtained and compared in Figure 9. The first-order model seems to be incompatible for describing the mechanisms due to low $\mathrm{R}^{2}$ value. The model yields poor linearity because it did not take into account the inherent complexity involved in the release process $\left(R^{2}=0.54\right)$. The Bhaskar model also gives a poor linearity $\left(R^{2}=0.66\right)$ as the model did not deal with the possibilities of both dissolution of the inorganic host and the anion exchange of the hybrid [52].

The fitting of release data is best achieved with the modified Freundlich model $\left(R^{2}=0.98\right)$, followed by parabolic diffusion $\left(R^{2}=0.96\right)$ which suggest that the release process is of diffusion-controlled. Note that high $R^{2}$ value of the latter model is due to the "grouping" of the data towards low values on the $x$-axis, which is often observed upon applying this model for the kinetic analysis in layered hydroxides [18,53]. Generally, there are two governing mechanisms in the release system of layered double hydroxides (LDH); anion diffusion through particles and dissolution of the LDH particles [49]. The modified Freundlich model which concerns with the heterogeneous diffusion from flat surfaces via ion exchange would describe better the release process in Z-CFX; surface CFX anions diffused first into the PBS medium and underwent exchange with phosphate ions in the medium. The process was followed by diffusion from the interlayer anions. The latter process being designated as the rate limiting step [51]. We would attribute the sustained release of CFX anions due to the strong coordination bond which occurred between the anions and the $\mathrm{Zn}$ ions of the $\mathrm{LZH}$ lattice.

\section{Toxicity study}

Figure 10 shows the A549 cancer cell proliferation profiles after treatment with the intercalation compound, Z-CFX, the host, LZH and free drug, CFX for $72 \mathrm{~h}$. Cell viability was measured using the MTT assay, which is based on the reduction of yellow tetrazolium MTT salt by metabolically active cells, leading to the formation of purple formazan crystals [54]. In general, all the three samples exerted toxic effects towards the A549 cells as the concentration increases. Upon comparing the $\mathrm{IC}_{50}$; the concentration that inhibits $50 \%$ of the cellular growth, Z-CFX shows lower $\mathrm{IC}_{50}$ compared with the value of free drug; $18.2 \pm 3.2 \mu \mathrm{g} / \mathrm{mL}$ and $78.3 \pm 2.5 \mu \mathrm{g} / \mathrm{mL}$, respectively. This finding indicates that the compound has higher inhibitory effects towards the A549 cells compared to that of free drug. It is worth mentioning that precursor LZH has significantly as much as 8 times less toxicity than the intercalation compound (Figure 9c). 

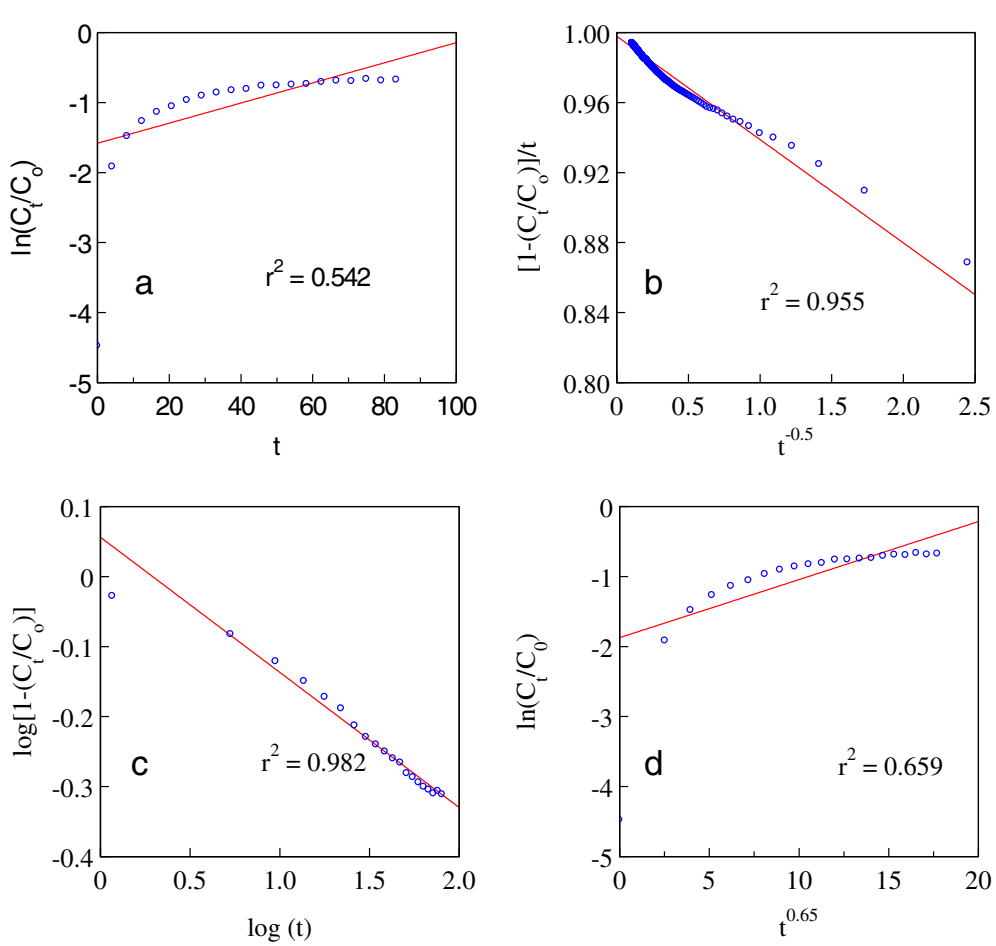

Figure 9 Release data of CFX from Z-CFX into PBS solution pH 7.4 Fitted to four kinetic models. (a) first order model, (b) parabolic diffusion model, (c) modified freundlich model, (d) bhaskar model.

Al Ali et al. [47] found that zinc layered hydroxides intercalated with hippuric acid possessed synergistic effects with tamoxifen towards HepG2 cells in which the $\mathrm{IC}_{50}$ value significantly decreased than that of tamoxifen and hippuric acid alone. $\mathrm{Li}$ et al. [33] pointed out that decreased viability of HeLa cancer cells was due to LDH intercalation with folic acid which protected the anticancer drug from degradation and enhanced its permeability into the target cells. Considering the sustained release behavior of Z-CFX, we would attribute the enhanced antiproliferative effects observed in Z-CFX is due to the strong interactions occurred between LZH and CFX; the host would facilitate the cell uptake and further protect the guest from degradation so that the anions were slowly released and "killed" the A549 cells [55].

\section{Conclusions}

CFX was successfully intercalated into the interlayers of layered zinc hydroxides via anion exchange mechanism in water:organic solvent mixture solution. The basal spacing of LZH was expanded to maximize the drughost interactions in the intercalation compound, Z-CFX in which the intercalated CFX anions were bonded to tetrahedral $\mathrm{Zn}^{2+}$ moieties of the lattice in a unidentate

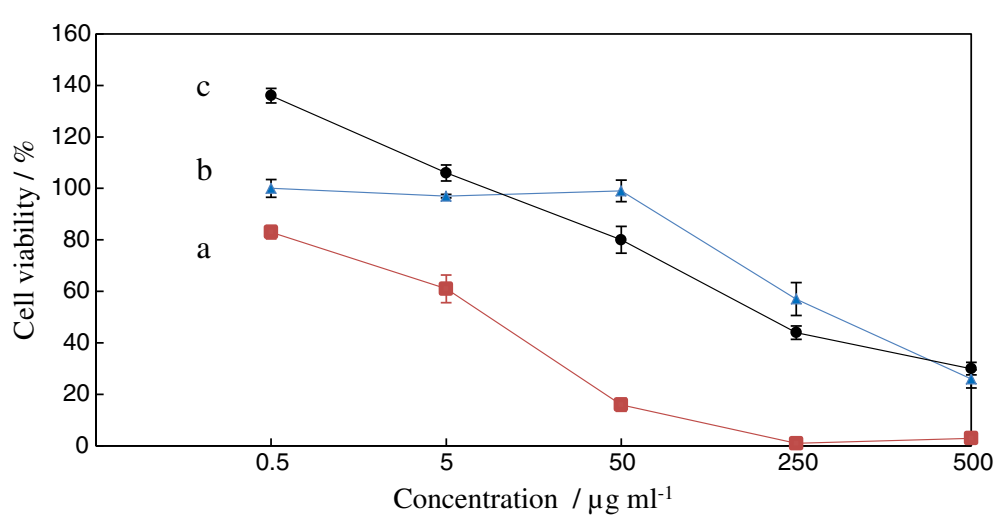

Figure 10 Dose response curve of A549 cell proliferation throughout 72 hours. (a) intercalation compound, Z-CFX. (b) free drug molecule, CFX. (c) host material, LZH. 
coordination mode. Due to strong coordination bond between drug-host lattice, the intercalated anions were slowly released, following diffusion-anion exchange mechanisms in which diffusion from the interlayer anions being the rate limiting step. The antiproliferative towards A549 cells were enhanced due to the synergistic effects between CFX and LZH. These findings should serve as strong foundations in further development of biocompatible LZH-based drug carrier.

\section{Abbreviations}

LHS: Layered hydroxide salts; LZH: Layered zinc hydroxide nitrate; CFX: Ciprofloxacin; Z-CFX: Layered zinc hydroxide nitrate intercalated with ciprofloxacin; H: Hour/hours; ${ }^{\circ}$ : Celcius degree; g: Gram; XRD: Powder x-ray diffraction; L: Liter; $\mathrm{mL}$ : Milliliter; FTIR: Fourier transform infrared;

TGA: Thermogravimetric analysis; PBS: Phosphate-buffered saline; ZnO: Zinc oxide; Min: Minutes; BET: Brunauer-Emmett-Teller; BJH: Barrett-JoynerHelenda.

\section{Competing interests}

The authors declare they have no competing interests.

\section{Authors' contributions}

AFL prepared materials, analyzed and interpreted data and worked on the manuscript. MZH proposed the research and convened scientific personnels and assisted in the manuscript write-ups. JS oversaw the progress of toxicity screenings while WCC conducted the MTT assay and contributed to data interpretation. RA helped in TGA and reviewed the manuscript. All authors read and approved the final manuscript.

\section{Authors' information}

Prof. Dr. Mohd Zobir Hussein is professor of chemistry at the Institute of Advanced Technology, Universiti Putra Malaysia. His major research areas include layered organic-inorganic nanohybrid for gene and drug delivery, nanoparticles and nanostructured materials, their design, synthesis and applications. He has contributed to more than 200 technical papers. He is the assignor of 1 granted patent on the preparation method of nanomaterial for controlled release formulation and co-assignor of another 2 granted patents. In December 2012, he was awarded as one of Malaysia's top scientist researcher by the government of Malaysia.

\section{Acknowledgements}

This work is financially supported by the Ministry of Higher Education, Malaysia through the ERGS grant No. ERGS/1/11/STG/UPM/01/18. AFL is thankful for the ASTS fellowship from Universiti Sains Malaysia.

\section{Author details}

'Materials Synthesis and Characterization Laboratory (MSCL), Institute of Advanced Technology (ITMA), Universiti Putra Malaysia UPM, 43400 Serdang, Selangor, Malaysia. ${ }^{2}$ Pharmacotherapeutics Unit, Department of Medicine, Faculty of Medicine and Health Sciences, Universiti Putra Malaysia UPM, 43400 Serdang, Selangor, Malaysia. ${ }^{3}$ School of Chemical Sciences, Universiti Sains Malaysia, 11800 Pulau, Pinang, Malaysia.

Received: 8 March 2013 Accepted: 27 June 2013

Published: 12 July 2013

\section{References}

1. Hoffman AS: The origins and evolution of "controlled" drug delivery systems. J Controlled Release 2008, 132:153-163.

2. Lammers T, Kiessling F, Hennink WE, Storm G: Nanotheranostics and image-guided drug delivery: current concepts and future directions. Mol Pharm 2010, 7:1899-912.

3. Farokhzad OC, Langer R: Impact of nanotechnology on drug delivery. ACS Nano 2009, 3:16-20.

4. Bhardwaj V, Ravi Kumar MNV: Drug delivery systems to fight cancer. In Fundamentals and applications of controlled release drug delivery: advances in delivery science and technology. Edited by Siepmann J, Siegel RA, Rathbone MJ. London: Springer; 2012:493-416
5. Tsung J, Burgess DJ: Biodegradable polymers in drug delivery systems. In Fundamentals and applications of controlled release drug delivery: advances in delivery science and technology. Edited by Siepmann J, Siegel RA, Rathbone MJ. London: Springer; 2012:107-123.

6. Evans DG, Slade RCT: Structural aspects of layered double hydroxides. In Structure and bonding. Edited by Evans DG. Berlin Heidelberg: Springer; 2006:1-87.

7. Newman SP, Jones W: Comparative study of some layered hydroxide salts containing exchangeable interlayer anions. J Solid State Chem 1999, 148:26-40.

8. Biswick T, Jones W, Pacula A, Serwick E: Synthesis, characterisation and anion exchange properties of copper, magnesium, zinc and nickel hydroxy nitrates. I Solid State Chem 2006, 179:49-55.

9. Benard P, Auffredic JP, Louer D: A study of the thermal decomposition of ammine zinc hydroxide nitrates. Thermochim Acta 1994, 232:65-76.

10. Biswick T, Park DH, Shul YG, Choy JH: P-coumaric acid-zinc basic salt nanohybrid for controlled release and sustained antioxidant activity. J Phys Chem Solids 2010, 71:647-649.

11. Zhang W, Yanagisawa K: Hydrothermal synthesis of zinc hydroxide chloride sheets and their conversion to ZnO. Chem Mater 2007, 19:2329-2334

12. Kandare $E$, Hossenlopp JM: Hydroxy double salt anion exchange kinetics: effects of precursor structure and anion size. J Phys Chem B 2005, 109:8469-8475.

13. Thomas N, Rajamathi M: Near $100 \%$ selectivity in anion exchange reactions of layered zinc hydroxy nitrate. J Colloid Interface Sci 2011, 362:493-496.

14. Marangoni R, Ramos LP, Wypych F: New multifunctional materials obtained by the intercalation of anionic dyes into layered zinc hydroxide nitrate followed by dispersion into poly(vinyl alcohol). J Colloid Interface Sci 2009, 330:303-309.

15. Demel J, Kubat P, Jirka I, Kovar P, Pospisil M, Lang K: Inorganic-organic hybrid materials: layered zinc hydroxide salts with intercalated porphyrin sensitizers. J Phys Chem C 2010, 114:16321-16328.

16. Rocca E, Caillet C, Mesbah A, Francois M, Steinmetz J: Intercalation in zinclayered hydroxide: zinc hydroxyheptanoate used as protective material on zinc. Chem Mater 20006, 18:6186-6193.

17. Mohd Zobir H, Al Ali SA, Zainal Z, Hakim MN: Development of antiproliferative nanohybrid compound with controlled release property using ellagic acid as the active agent. Int J Nanomedicine 2011, 6:1373.

18. Richardson-Chong SSD, Patel R, Williams GR: Intercalation and controlled release of bioactive ions using a hydroxy double salt. Ind Eng Chem Res 2012, 51:2913-2921.

19. Brighty KE, Gootz TD: Chemistry and mechanism of action of the quinolone antibacterials. In The quinolones. 3rd edition. Edited by Adriole V. London: Academic Press; 2000:33-97.

20. Stahlmann R, Lode H: Safety overview: toxicity, adverse effects and reactions. In The quinolones. 3rd edition. Edited by Adriole V. London: Academic Press; 2000:397-453.

21. Kelesidis T, Fleisher J, Tsiodras S: Anaphylactoid reaction considered ciprofloxacin related: a case report and literature review. Clin Ther 2010, 32:515-526

22. Kothur K, Singh M, Dayal D: Ciprofloxacin-induced anaphylactoid reaction. Eur J Pediatr 2006, 165:573-574.

23. Harder S, Fuhr U, Beermann D, Staib AH: Ciprofloxacin absorption in different regions of the human gastrointestinal tract. Investigations with the hf-capsule. Br J Clin Pharmacol 1990, 30:35-39.

24. How PP, Fischer JH, Arruda JA, Lau AH: Effects of lanthanum carbonate on the absorption and oral bioavailability of ciprofloxacin. Clin J Am Soc Nephrol 2007, 2:1235-1240.

25. Alvarez-Lorenzo C, Yanez F, Barreiro-Iglesias R, Concheiro A: Imprinted soft contact lenses as norfloxacin delivery systems. J Controlled Release 2006, 113:236-244.

26. Arnold MM, Gorman EM, Schieber LJ, Munson EJ, Berkland C: J: NanoCipro encapsulation in monodisperse large porous PLGA microparticles. J Controlled Release 2007, 121:100-109.

27. Chouhan R, Bajpai AK: Release dynamics of ciprofloxacin from swellable nanocarriers of poly(2-hydroxyethyl methacrylate): an in vitro study. Nanomedicine 2010, 6:453-462.

28. Blanchemain N, Karrouta Y, Tabarya N, Briaa M, Neuta C, Hildebrand HF, Siepmann J, Martel B: Comparative study of vascular prostheses coated 
with polycyclodextrins for controlled ciprofloxacin release. Carbohydr Polym 2012, 90:1695-1073.

29. Wang Q, Dong Z, Du Y, Kennedy JF: Controlled release of ciprofloxacin hydrochloride from chitosan/polyethylene glycol blend. Carbohydr Polym 2007, 69:336-343.

30. Wang CJ, Li Z, Jiang WT, Jean JS, Liu CC: Cation exchange interaction between antibiotic ciprofloxacin and montmorillonite. J Hazard Mater 2010, 183:309-314

31. Castro C, Sanchez E, Delgado A, Soriano I, Nunez P, Baroc M, Perera A, Evora C: Ciprofloxacin implants for bone infection. In vitro-in vivo characterization. J. Controlled Release 2003, 93:341-354.

32. Yang JH, Han YS, Park M, Park T, Hwang SJ, Choy JH: New Inorganic-based drug delivery system of indole-3-acetic acid-layered metal hydroxide nanohybrids with controlled release rate. Chem Mater 2007, 19:2679-2685.

33. Li Y, Liu D, Ai H, Chang Q, Liu D, Xia Y, Liu S, Peng N, Xi Z, Yang X: Biological evaluation of layered double hydroxides as efficient drug vehicles. Nanotechnology 2010, 21:1-13.

34. Arizaga GGC, Mangrich AS, Gardolinski JEFC, Wypych F: Chemical modification of zinc hydroxide nitrate and $\mathrm{Zn}$-Al-layered double hydroxide with dicarboxylic acids. J Colloid Interface Sci 2008, 320:168-176.

35. Khan Al, Ragavan A, Fong B, Markland C, O'Brien M, Dunbar TG, Williams GR, O'Hare D: Recent developments in the use of layered double hydroxides as host materials for the storage and triggered release of functional anions. Ind Eng Chem Res 2009, 48:10196-10205.

36. Li C, Wang G, Evans DG, Duan X: Incorporation of rare-earth ions in Mg-Al layered double hydroxides: intercalation with an [Eu(EDTA)] chelate. I Solid State Chem 2004, 177:4569-4575.

37. F. Kovanda F, Z. Maryskova Z, Kovar P: Intercalation of paracetamol into the hydrotalcite-like host. J Solid State Chem 2011, 184:3329-3335.

38. Hernandez-Gil J, Perello L, Ortiz R, Alzuet G, Gonzalez-Alvarez M, LiuGonzalez M: Synthesis, structure and biological properties of several binary and ternary complexes of copper(II) with ciprofloxacin and 1,10 phenanthroline. Polyhedron 2009, 28:138-144.

39. Aloisi GG, Costantino U, Elisei F, Latterini L, Natali C, Nocchetti M: Preparation and photo-physical characterisation of nanocomposites obtained by intercalation and co-intercalation of organic chromophores into hydrotalcite-like compounds. J Mater Chem 2002, 12:3316-3323.

40. Du Y, O'Hare D: Observation of staging during intercalation in layeredcobalt hydroxides: a synthetic and kinetic study. Inorg Chem 2008, 47:11839-11846.

41. Vieira AC, Moreira RL, Dias A: Raman Scattering and Fourier transform infrared spectroscopy of $\mathrm{Me}_{6} \mathrm{Al}_{2}(\mathrm{OH})_{16} \mathrm{Cl}_{2} \cdot 4 \mathrm{H}_{2} \mathrm{O}(\mathrm{Me})=\mathrm{Mg}, \mathrm{Ni}, \mathrm{Zn}, \mathrm{Co}$ and $\mathrm{Mn}$ ) and $\mathrm{Ca}_{2} \mathrm{Al}(\mathrm{OH})_{6} \mathrm{Cl} \cdot 2 \mathrm{H}_{2} \mathrm{O}$ hydrotalcites. J Phys Chem C 2009, 113:13358-13368.

42. Arizaga GGC, Satyanarayana KG, Wypych F: Layered hydroxide salts: synthesis, properties and potential applications. Solid State Ionics 2007, 178:1143-1162.

43. Zhi Y, Li Y, Zhang Q, Wang H: ZnO nanoparticles immobilized on flaky layered double hydroxides as photocatalysts with enhanced adsorptivity for removal of acid red G. Langmuir 2010, 26:15546-15553.

44. Auxilio AR, Andrews PC, Junk PC, Spiccia L, Neumann D, Raverty W, Vanderhoek N: Adsorption and intercalation of acid blue 9 on Mg-Al layered double hydroxides of variable metal composition. Polyhedron 2007, 26:3479-3490

45. Arco MD, Cebadera E, Gutierrez S, Martin C, Montero MJ, Rives V, Rocha J, Sevilla MA: Mg, Al layered double hydroxides with intercalated indomethacin: synthesis, characterization, and pharmacological study. J Pharm Sci 2004, 93:1649-1658

46. Rojas R, Ulibarri MA, Barriga C, Rives V: Intercalation of metal-EDTA complexes in $\mathrm{Ni}-\mathrm{Zn}$ layered hydroxysalts and study of their thermal stability. Microporous Mesoporous Mater 2008, 112:262-272.

47. Al Ali SHH, Al-Qubaisi M, Hussein MZ, Zainal Z, Hakim MN: Preparation of hippurate-zinc layered hydroxide nanohybrid and its synergistic effect with tamoxifen on HepG2 cell lines. Int J Nanomed 2011, 6:3099-3111.

48. Malherbe F, Forano C, Besse JP: Use of organic media to modify the surface and porosity properties of hydrotalcite-like compounds. Microporous Mater 1997, 10:67-84

49. Panda HS, Srivastava R, Bahadur D: In-vitro release kinetics and stability of anticardiovascular drugs-intercalated layered double hydroxide nanohybrids. J Phys Chem B 2009, 113:15090-15100.
50. VH Nguyen TD, Narb M, D'Souza NA, Golden TD: Polymer nanocomposites for improved drug delivery efficiency. Mater Chem Phys 2012, 132:409-415.

51. Gu Z, Thomas AC, Xu P, Campbell JH, Lu GQ: In vitro sustained release of LMWH from MgAl-layered double hydroxide nanohybrids. Chem Mater 2008, 20:3715-3722.

52. Bhaskar R, Murthy RSR, Miglani BD, Viswanathan K: Novel method to evaluate diffusion controlled release of drug from resinate. Int J Pharm 1986, 28:59-66.

53. Markland C, Williams GR, D. O'Hare D: The intercalation of flavouring compounds into layered double hydroxides. J Mater Chem 2011, 21:17896-17903.

54. Choi SJ, Choi GE, Oh JM, Oh YJ, Park MC, Choy JH: Anticancer drug encapsulated in inorganic lattice can overcome drug resistance. J Mater Chem 2010, 20:9463-9469.

55. Gu Z, Rolfe BE, Xu ZP, Thomas AC, Campbell JH, Lu GQ: Enhanced effects of low molecular weight heparin intercalated with layered double hydroxide nanoparticles on rat vascular smooth muscle cells. Biomaterials 2010, 31:5455-5462.

doi:10.1186/1752-153X-7-119

Cite this article as: Abdul Latip et al:: Release behavior and toxicity profiles towards A549 cell lines of ciprofloxacin from its layered zinc hydroxide intercalation compound. Chemistry Central Journal 2013 7:119.

Publish with ChemistryCentral and every
scientist can read your work free of charge
"Open access provides opportunities to our
colleagues in other parts of the globe, by allowing
anyone to view the content free of charge."
W. Jeffery Hurst, The Hershey Company.
- available free of charge to the entire scientific community
- peer reviewed and published immediately upon acceptance
- cited in PubMed and archived on PubMed Central
- yours - you keep the copyright
submit your manuscript here:
http://www.chemistrycentral.com/manuscript/

